\title{
Electrical arrhythmias in the human stomach
}

\author{
C J STODDARD, R H SMALLWOOD, AND H L DUTHIE* \\ From the Departments of Surgery and Medical Physics, Royal Hallamshire Hospital, Sheffield
}

SUMMARY Myoelectrical activity was recorded from the human antrum on 136 occasions using a monopolar mucosal electrode in preoperative and post-vagotomy patients, and bipolar serosal electrodes in post-cholecystectomy patients, and the incidence of antral arrhythmias observed. Arrhythmias of long duration were observed in five out of 62 patients after vagotomy and one out of 10 patients after cholecystectomy, but not in preoperative patients. They were characterised by slow waves with increased frequency, variable period, amplitude, and wave shape and were associated with periods of slow wave inhibition. None of the patients with an arrhythmia had any symptoms of disordered gastric motility. Antral arrhythmias could also be induced in some patients by the administration of insulin, secretin, cholecystokinin-pancreozymin, glucagon, and pentagastrin. The appearance of antral arrhythmias is probably due to a relative increase of sympathetic over parasympathetic activity. The maximal slow wave frequency observed was 8.3 cycles per minute and it is probable that in vivo human antral smooth muscle has a maximum frequency above which it cannot be driven.

Gastric myoelectrical activity is characterised by the presence of regular slow waves in the distal two-thirds of the stomach, the orad third being an electrically silent area. The mean slow wave frequency is speciesdependent, being approximately $3 \mathrm{c} / \mathrm{min}$ in $\operatorname{man}^{12}$ and $5 \mathrm{c} / \mathrm{min}$ in dogs ${ }^{3{ }^{4}}$ with little day-to-day variation. The rhythm is normally remarkably stable, with only occasional irregularities of a few cycles' duration. ${ }^{5}$ Although periods of faster, irregular activity have been found on rare occasions in dogs with intact stomachs, ${ }^{6}$ they have been observed more frequently after vagotomy. ${ }^{78}$ Antral arrhythmias can be induced in dogs with intact vagi by infusion of adrenaline, atropine, morphine, and large doses of histamine, ${ }^{10}$ and are attributable to the development of ectopic pacemakers in the antrum. Daniel concluded that the appearance of antral arrhythmias corresponds with the dominance of sympathetic over parasympathetic activity. Two types of abnormal myoelectrical activity have been described; a tachygastria characterised by an increased frequency of slow waves with regular periods, wave shapes, and amplitudes, and a tachyarrhythmia where the slow waves are faster but have irregular periods and configurations. ${ }^{11}$

Although irregular myoelectrical activity in the human stomach was reported in some patients with

${ }^{*}$ Present address: Provost. Welsh National School of Medicine, Cardiff.

Received for publication 28 January 1981 gastric or oesophageal carcinomata ${ }^{12-14}$ and thought to be of diagnostic importance, these initial observations and expectations have not been confirmed by further studies. However, two recent articles have implicated antral arrhthymias as the aetiological factor in the development of certain gastric motility disturbances. Telander $e t$ al. ${ }^{15}$ described an infant with intractable gastric stasis due to a persistent antral arrhythmia with an ectopic distal antral pacemaker and You et al. ${ }^{16}$ observed antral arrhythmias in all nine patients with unexplained nausea, bloating, and vomiting, from whom they were able to obtain satisfactory recordings. Although You et al.$^{16}$ did study a small number of normal subjects (nine), the incidence of antral arrhythmias in asymptomatic volunteers has not previously been reported.

This paper describes our experience of antral arrhythmias in patients with no gastroduodenal pathology, with chronic duodenal ulceration studied before and after vagotomy, in the early postoperative period after cholecystectomy and, finally, in certain subjects after administration of various drugs and hormones.

\section{Methods}

One hundred and four patients were studied on 136 separate occasions (Table 1). Informed consent was 705 
Table 1 Status of patients from whom electrical recordings were obtained

\begin{tabular}{lrr}
\hline Total number of subjects studied & & 104 \\
Total number of recording sessions & & 136 \\
$\quad$ Preoperative recordings & 54 \\
$\quad$ Subjects with no gastroduodenal disease & 15 & \\
$\quad$ Duodenal ulcer patients & & 62 \\
Postvagotomy recordings & 37 & \\
$\quad$ Truncal vagotomy and pyloroplasty & 20 \\
$\quad$ Highly selective vagotomy & 5 & \\
Selective vagotomy and pyloroplasty & & 20 \\
Postcholecystectomy recordings & & \\
\hline
\end{tabular}

obtained before the performance of each test. Fiftyfour subjects were studied preoperatively; 15 were awaiting surgery for chronic duodenal ulceration and 39 were patients with a variety of minor surgical conditions, but without symptoms of gastroduodenal disease, who agreed to undergo the study. Sixty-two recordings were obtained from 57 patients after vagotomy, 23 on the fifth postoperative day, and 39 between 14 days and 11 years after operation. Thirtyseven of these recordings were after truncal vagotomy and pyloroplasty (TV), 20 after highly selective vagotomy (HSV), and five after selective vagotomy and pyloroplasty (SV). Five patients (three after TV and two after HSV) were studied both on the fifth postoperative day and between six and 13 months after operation.

These patients were fasted overnight and a modified nasogastric tube, identical to that previously used in this department, ${ }^{\prime}$ was passed into the gastric antrum under radiographic control and attached to the gastric mucosa by suction, which was maintained for the duration of the test. Monopolar recordings of myoelectrical activity were made from a stainless steel electrode situated $1 \mathrm{~cm}$ from the tip of the tube, the indifferent electrode being a metal disc applied to the scarified skin over the right iliac fossa. Signals from the electrode were fed into an amplifier with a frequency response within $\pm 3 \mathrm{~dB}$ from $0.016 \mathrm{~Hz}$ to 1.0 $\mathrm{KHz}$ and then displayed on a $\mathrm{u}-\mathrm{v}$ recorder. The amplifier output was band-pass filtered (frequency response 2 to $6 \mathrm{c} / \mathrm{min}( \pm 3 \mathrm{~dB}$ from 0.016 to $1.0 \mathrm{kHz})$ ) and the filter output also displayed on the $u-v$

Table 2 Number of patients receiving each drug or hormone

\begin{tabular}{lllll}
\hline $\begin{array}{l}\text { Drug/hormone } \\
\text { administered }\end{array}$ & \multicolumn{4}{l}{ Patients status } \\
\cline { 2 - 5 } & Pre-op & Post-HSV & Post-TV & Post-SV \\
\hline Pentagastrin & 19 & - & - & - \\
Insulin & - & 11 & 20 & 2 \\
Secretin & 4 & - & - & - \\
CCK-PZ & 8 & - & - & - \\
Glucagon & 3 & 7 & 3 & 1 \\
\hline
\end{tabular}

recorder. Gastric secretion was continuously aspirated via an attached tube.

After a 30 minute time lapse, during which the subjects became accustomed to the tube, residual gastric contents were aspirated and electrical connections established, recordings were commenced with the subjects in a semirecumbent position. A 60 minute control study was performed in each patient at each recording session. At the end of this period, various drugs and gastrointestinal hormones were administered to a number of patients and their effects observed during an additional one to two hours' recording. The number of patients receiving each preparation is shown in Table 2. The dose rates and methods of administration are as follows: soluble insulin $0.2 \mathrm{IU} / \mathrm{kg}$ intravenously; secretin 0.25 and 2.0 clinical units $/ \mathrm{kg} / \mathrm{h}$ (from GIH Research Unit, Karolinska Institute, Stockholm) infused intravenously over 30 minutes, preceded and followed by a 30 minute infusion of 0.15 molar saline; cholecystokinin-pancreozymin (CCK-PZ) 1.0 and 16.0 Crick, Harper, Raper units $/ \mathrm{kg} / \mathrm{h}$ (from GIH Stockholm) infusions; glucagon (Eli Lilly) in sequential intravenous doses of 2,5 , and $10 \mu \mathrm{g} / \mathrm{kg}$ body weight, and pentagastrin $6 \mu \mathrm{g} / \mathrm{kg}$ body weight intramuscularly (ICI Pharmaceuticals).

Finally, in 10 other consenting patients undergoing elective cholecystectomy, a pair of stainless steel electrodes, $1 \mathrm{~cm}$ apart, were attached to the serosal surface of the antrum and the connecting wires exteriorised via a right hypochondrial stab incision along with a corrugated rubber drain. These electrodes were implanted in the muscular wall of the antrum in its longitudinal axis and held in position by a single 000 plain catgut suture. Two three hour bipolar myoelectrical recordings were made from each patient between the third and fifth postoperative days and after a fast of at least 12 hours. The drain and electrodes were uneventfully removed from all patients on the fifth postoperative day.

None of the patients studied preoperatively had any nausea, bloating, or vomiting. Similarly, none of the postoperative patients complained of bloating or vomiting, although six of those patients studied in the first five days after surgery did have some nausea.

The mean slow wave frequency during the periods of faster activity ( $F$ mean) in those subjects with arrhythmias was calculated by summing the number of individual slow waves during each of these periods and dividing by the total duration of all periods of faster activity, the frequency being expressed in cycles/minute. $\mathrm{F}$ max is the maximum slow wave frequency observed during any one minute period of faster activity. Statistical analyses were performed using Fisher's exact test. 


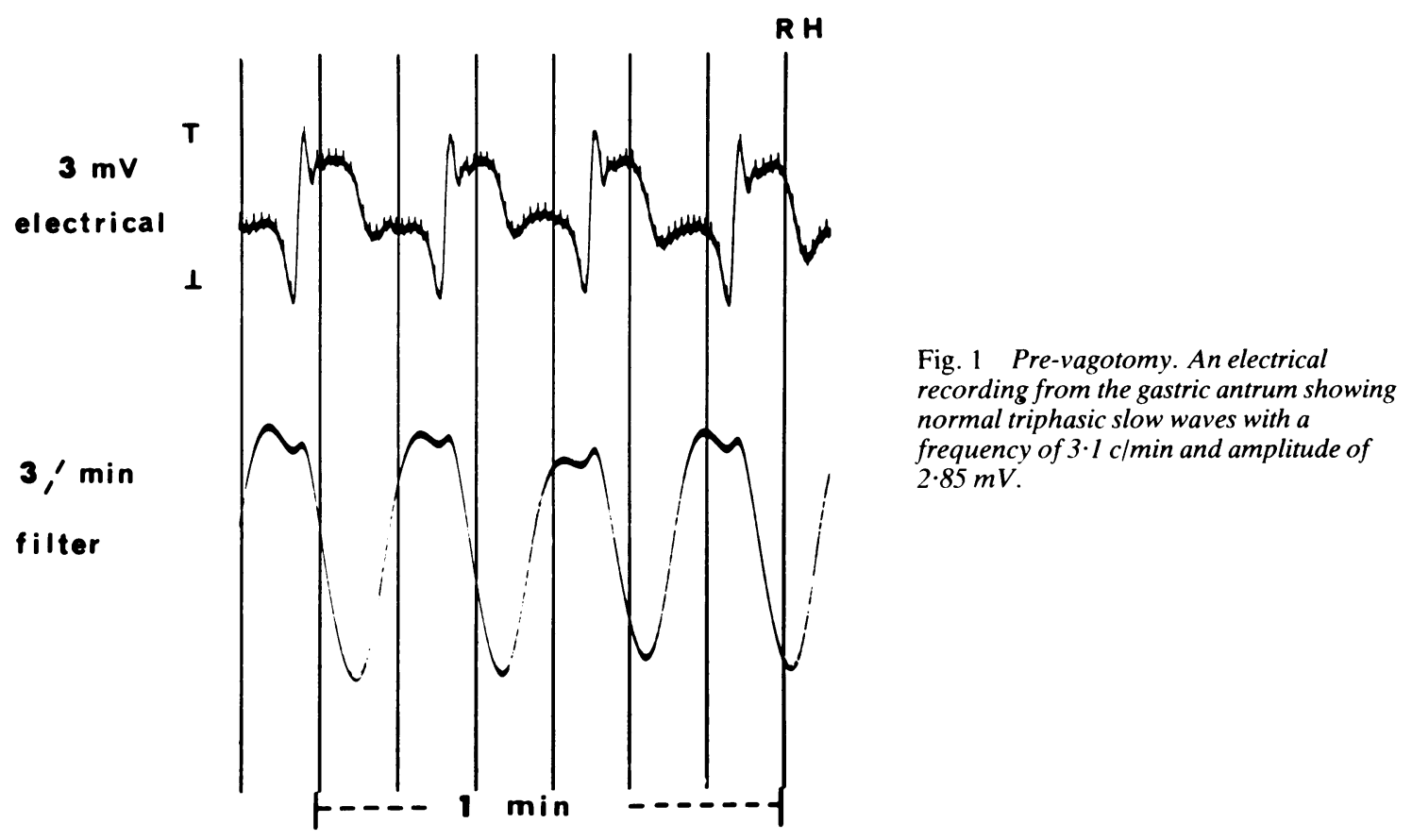

\section{Results}

\section{MUCOSAL ELECTRODE}

\section{Control period}

Previous studies in this department have shown that, in preoperative patients, there are no significant differences in antral myoelectrical activity between 'normal' subjects and duodenal ulcer patients ${ }^{17}$ and the results have been expressed as one group. Regular slow waves with a mean frequency of $3 \cdot 10$ $\pm 0.03 \mathrm{c} / \mathrm{min}$ and mean amplitude of $2 \cdot 04 \pm 0.05 \mathrm{mV}$ were recorded throughout the control period in 53 of the 54 subjects (Fig. 1). Irregular activity was recorded from only one patient and this did not arise spontaneously but occurred as a result of retching, a situation in which abnormal electrical activity may occur. ${ }^{18}$ It was only of six minutes' duration and consisted of a tachygastria, the slow waves having a mean frequency of $7.2 \mathrm{c} / \mathrm{min}$, and a short period of slow wave inhibition lasting 72 seconds. At all other times, regular slow wave activity was present.

After vagotomy, antral arrhythmias were observed in five of the 62 recordings (post $\mathrm{HSV}$-one, post TV-four), these recordings being made five days and five, 11, 27, and 51 months after operation. Irregular activity was present for $23 \%$ and $90 \%$ of the control recording period in two subjects and in three other subjects was present for the entire 60 minute control period (Fig. 2). All four patients studied some months after operation were completely asymptomatic, with no evidence of a gastric motility disturbance. Although tachyarrhythmias and tachygastrias were seen in all patients, the predominant irregularity of rhythm in each recording was a tachyarrhythmia. F mean of the faster waves was $6.6 \mathrm{c} / \mathrm{min}$ (range 4.5 to 7.9) and $F$ max for each patient ranged from $6 \cdot 3$ to $7 \cdot 9$ $\mathrm{c} / \mathrm{min}$. Alternating with the periods of tachygastria and tachyarrhythmia were periods of slow wave inhibition of mean duration 48 seconds (range 16 to 113 seconds). Although antral arrhythmias were more frequent after TV (four of 37 recordings) than in preoperative studies (one of 54), the difference was not statistically significant. The incidence of arrhythmias after TV was statistically no different to that after HSV.

In four subjects with arrhythmias after vagotomy, attempts were made to stabilise the irregular activity pharmacologically. Two patients (one post-HSV and one post-TV) were given intravenous atropine 0.2 $\mathrm{mg}$, and in each case this was followed by the appearance of regular slow waves (Fig. 3). The regular activity appeared five minutes after injection and lasted 14 minutes in the post HSV patient and appeared 6.5 minutes after injection and lasted 7.5 minutes after TV. An additional injection of atropine had the same effect in each patient. Another post-TV patient was given propranolol $0.4 \mathrm{mg}$ intravenously and this was also followed by the appearance of 


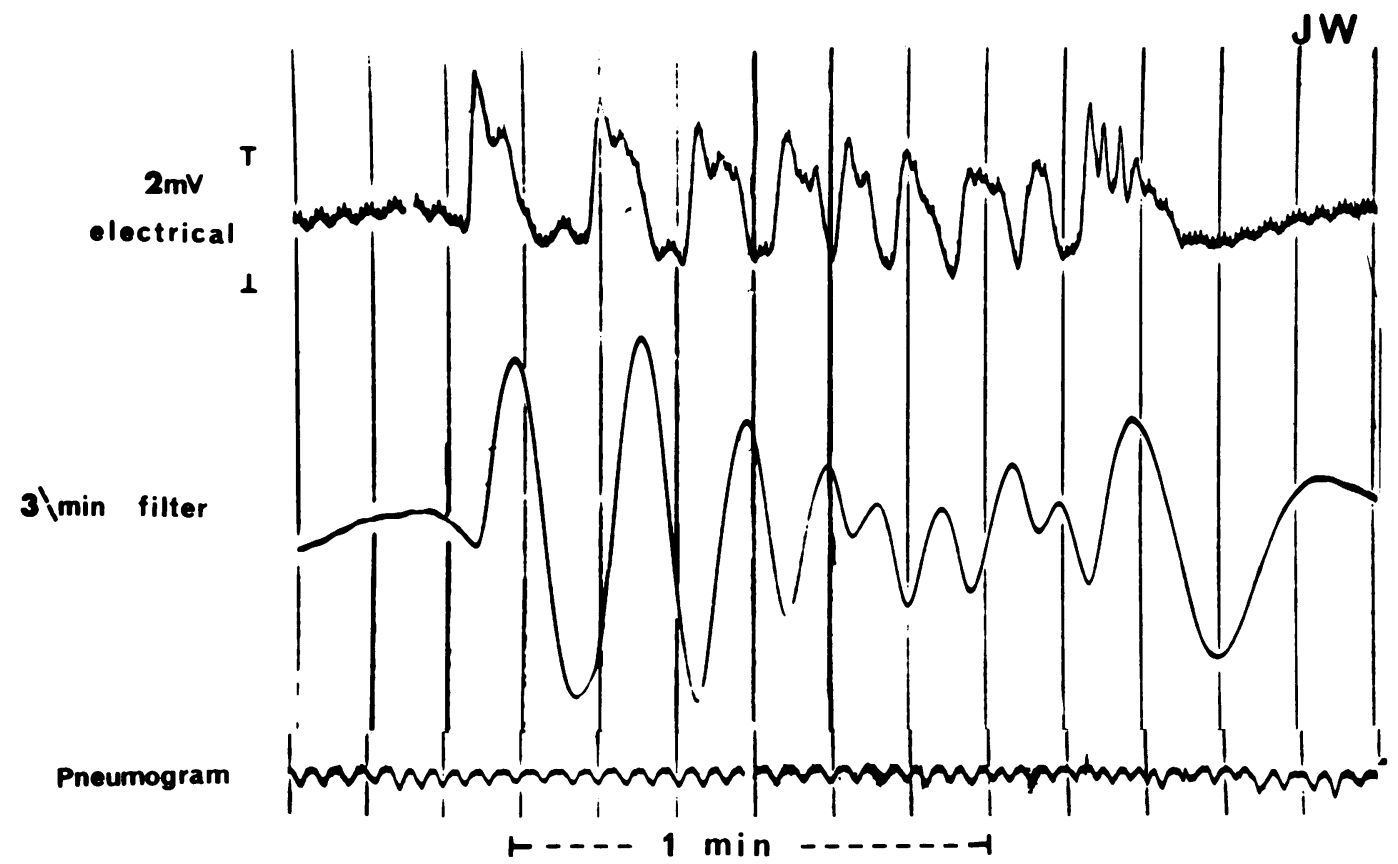

Fig. 2 Eleven months post-HSV. An electrical recording from the gastric antrum of a patient 11 months after HSV. Irregular activity is present and slow waves of varying wave shape, amplitude and period can be seen alternating with periods of inhibition.

regular activity. Thus, both atropine and propranolol abolished the antral arrhythmias.

EFFECTS OF DRUGS AND HORMONES Insulin

For all subjects, the highest frequency recorded $(\mathrm{F}$ $\max$ ) was $8.3 \mathrm{c} / \mathrm{min}$. The ratio between $\mathrm{F} \max$ and the mean frequency of the regular electrical waves during the control period for each subject varied between 1·53:1 and $2 \cdot 76: 1$ (mean $2 \cdot 32: 1$ ).

Thirty-three post-vagotomy patients received insulin. Seven patients $(21 \%)$ had irregular activity (postHSV-three; post-SV-one; post-TV-three), all of whom had negative gastric secretory responses based on Hollander's criteria. ${ }^{19}$ Tachyarrhythmias and

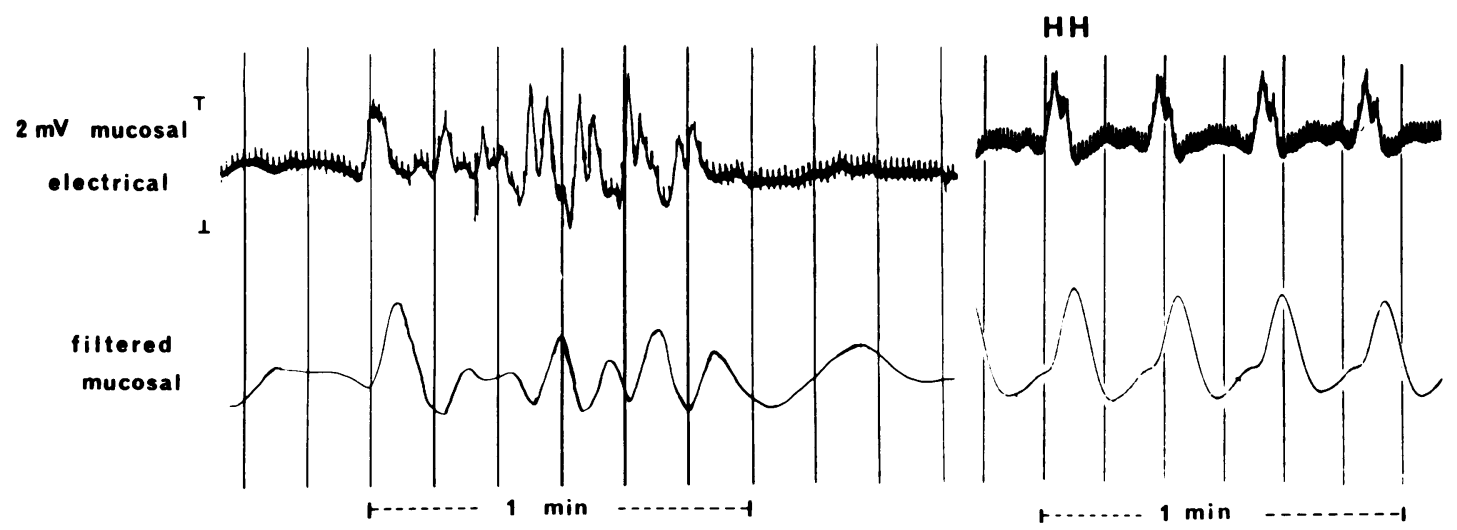

A F T ER

ATROPINE I V

Fig. 3 Two and a quarter years post-TV. A recording from a patient after TV showing irregular gastric electrical activity during the control period, which becomes stable after intravenous atropine. 


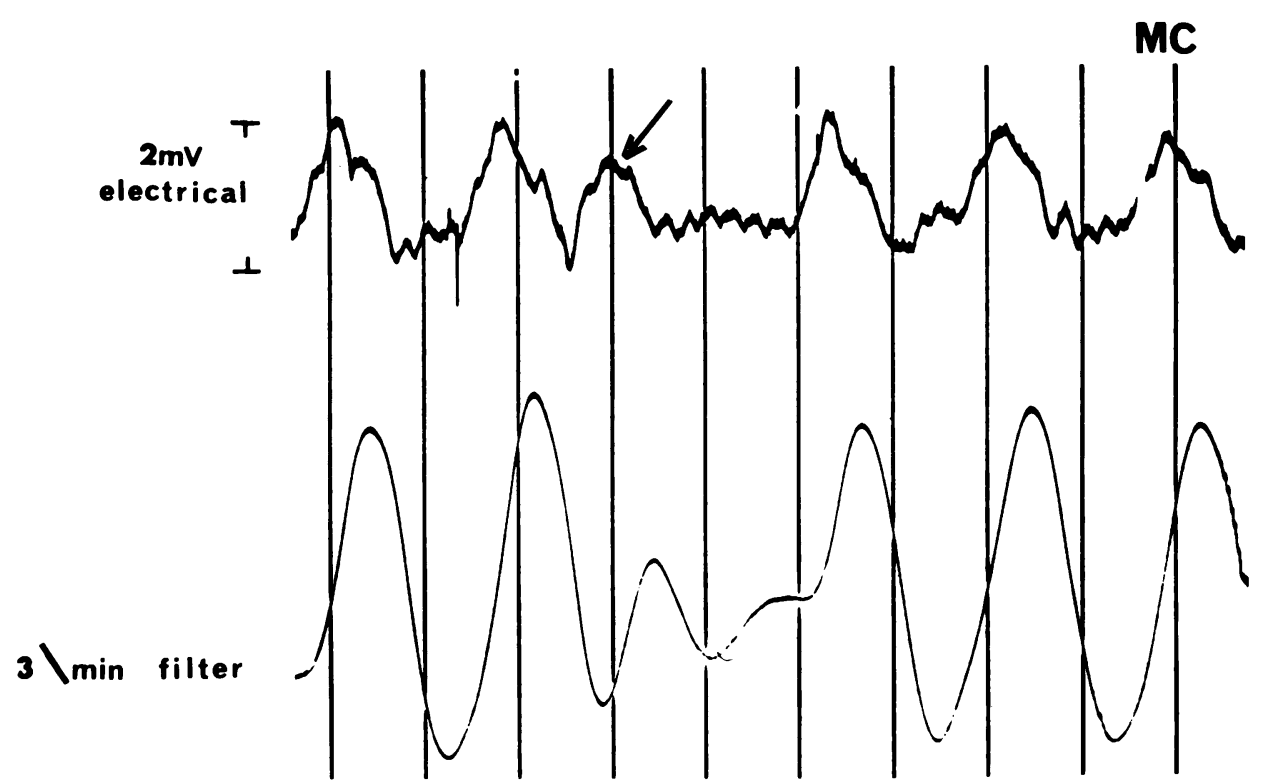

Fig. 4 Five years post-TV. A recording showing a premature potential (arrowed). The next anticipated slow wave in the series is absent, there being a short period of electrical inactivity.

periods of inhibition were seen in five patients, but in the other two (SV-one; TV-one), only periods of inhibition occurred. $F$ mean of the faster activity was $7 \cdot 4 \mathrm{c} / \mathrm{min}$ and the range of $\mathrm{F}$ max was $7 \cdot 3$ to $8 \cdot 2 \mathrm{c} / \mathrm{min}$. The mean duration of the periods of inhibition was 78 seconds (range 21-190).

In three patients, premature potentials were observed on 11 occasions. After each premature potential the next anticipated slow wave was absent (Fig. 4). The amplitudes of these premature potentials were less than the amplitudes of the normal slow waves.

\section{Secretin}

At a dose rate of $0 \cdot 25 \mu / \mathrm{kg} / \mathrm{h}$, short periods of inhibition were observed in one patient. At the higher dose rate inhibition occurred in all four patients and in three there were associated tachyarrhythmias. The longest period of irregular activity lasted for 19 minutes.

\section{Cholecystokinin-pancreozymin}

At the lower infusion rate, periods of inhibition were seen in two patients and a significant frequency reduction occurred in two others. At the higher infusion rate, three patients had periods of inhibition and three a reduced frequency but in no patient was faster activity observed.

\section{Glucagon}

The slow wave frequency decreased within three minutes of injection at doses of 5 and $10 \mu \mathrm{g} / \mathrm{kg}$ body weight in all three preoperative patients and this was followed by a tachyarrhythmia, or tachygastria, with associated periods of inhibition. $F \max$ for these patients was between 6.0 and $8.3 \mathrm{c} / \mathrm{min}$. Identical changes were observed in seven patients after HSV (Fig. 5), the only difference between these and the preoperative recordings being that some patients after HSV were more responsive to the $2 \mu \mathrm{g} / \mathrm{kg}$ dose. Irregular activity and inhibition was observed in only one of the four patients studied after total gastric denervation. In two other patients there was a frequency reduction but no periods of inhibition.

\section{Pentagastrin}

Irregular activity was seen in one of the 19 patients who received pentagastrin, this occurring 30 minutes after administration of the drug. A single period of tachygastria occurred ( $\mathrm{F}$ mean $6.3 \mathrm{c} / \mathrm{min}$ ) with an associated period of inhibition lasting 110 seconds.

\section{SEROSAL ELECTRODES}

Episodes of tachyarrhythmia followed by periods of inhibition (Fig. 6) were observed in the recordings from one of the 10 patients studied within the first five days after cholecystectomy. This irregular activity was present during the recording period for three out of 150 minutes on the third postoperative day, and 18 out of 145 minutes on the fourth postoperative day. 


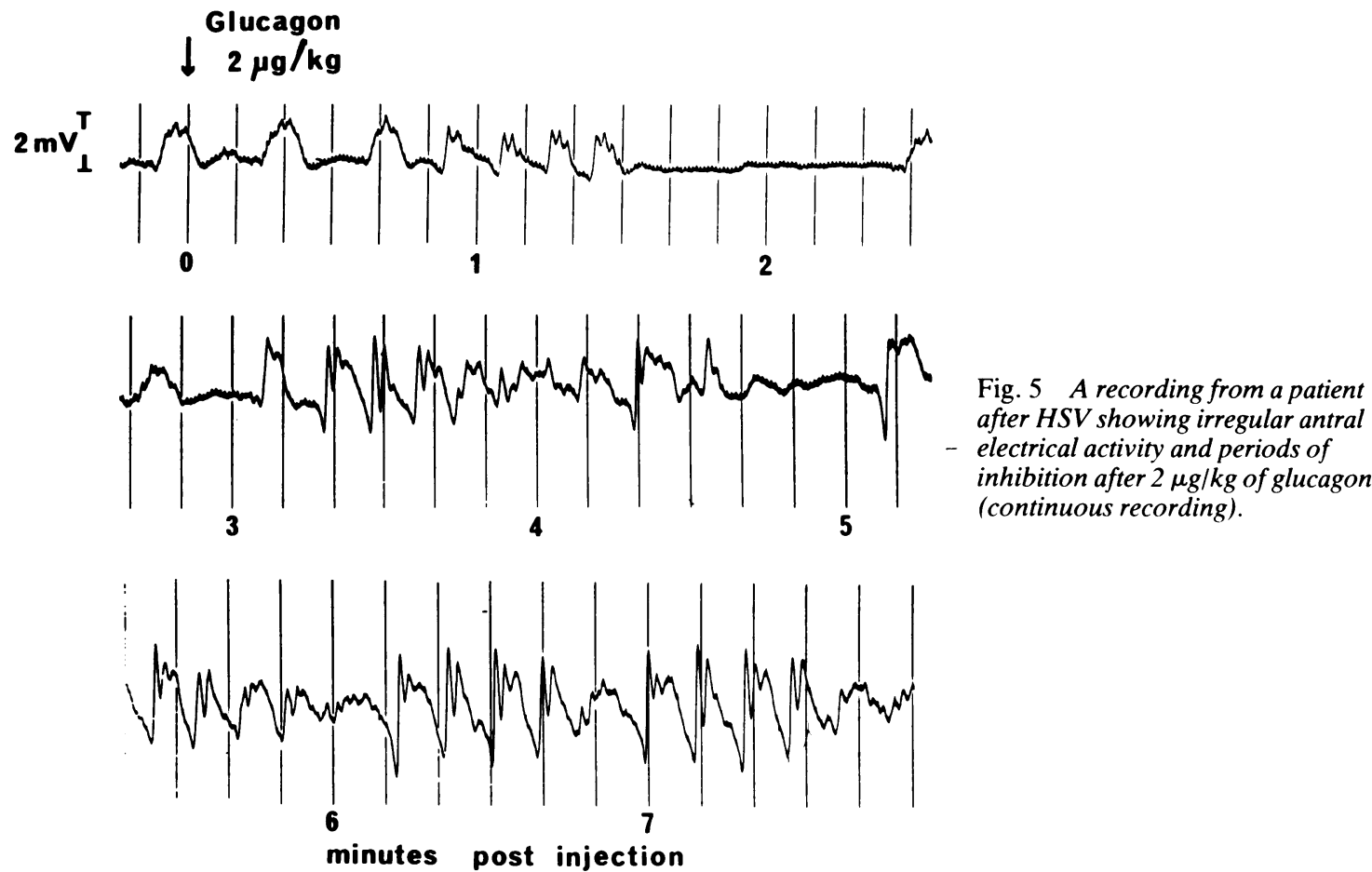

\section{Discussion}

In this study, we have not observed antral arrhythmias in asymptomatic preoperative patients in normal circumstances. A brief tachygastria was observed in only one of the 54 patients studied preoperatively and this was induced by retching. In contrast, the arrhythmias which were observed after vagotomy were of longer duration, being present for the entire control recording period in three patients. The association between an antral arrhythmia and a disturbance in gastric motility remains unclear. Although all nine patients with an antral arrhythmia studied by You ${ }^{16}$ had nausea, vomiting, and bloating, none of the five patients in this study with an arrhythmia had any upper gastrointestinal symptoms at all. Gastric emptying studies were not performed in any of our patients and, although it is possible that an antral arrhythmia may be associated with a delay in gastric emptying, none of our patients was symptomatic.

Premature gastric potentials were observed in three patients with loss of the next expected slow wave. The probable explanation of this is the extinction of the next normal slow wave due to collision with the premature potential which is spreading in a retrograde direction from the ectopic pacemaker site and the inability of the normal slow wave to be propagated throughout the gastric smooth muscle during

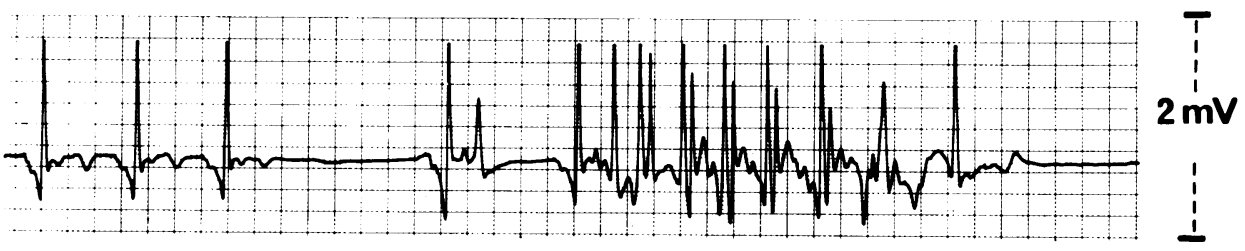

\section{-- 1 minute ---1}

Fig. 6 A recording using bipolar serosal electrodes from a postcholecystectomy patient showing normal antral slow waves followed by a period of inhibition and tacchyarrhythmia. 
the refractory period of the premature potential. These results suggest that human gastric smooth muscle may have a refractory period after depolarisation, similar to cardiac muscle. Premature potentials can be induced after the refractory period by both endogenous and exogenous stimuli with a possible corresponding increase in frequency of the electrical activity. The highest antral slow wave frequency, $F$ max, for all subjects in this series with antral arrhythmias, ranged between 4.5 and $8.3 \mathrm{c} / \mathrm{min}$, with the mean ratio of $F$ max to $F$ mean being $2 \cdot 32: 1$. Gastric pacing experiments have been performed in dogs using electrical stimulation ${ }^{6}$ and intra-arterial infusions of acetylcholine.$^{20}$ Premature gastric potentials could be induced after, but not before, $42 \%$ of an individual slow wave cycle had elapsed with a corresponding increase in frequency. Thus the maximum driven frequency of the canine gastric slow wave is approximately 2.5 times greater than the natural frequency. It appears that human gastric smooth muscle may also have a maximum frequency above which it cannot be driven.

Gastric myoelectrical activity is influenced by its extrinsic autonomic connections. In addition to the changes in human gastric slow wave characteristics which are dependent on the extent of the vagotomy, ${ }^{21}$ prolonged antral arrhythmias were seen in four patients after TV and one patient after HSV. Antral arrhythmias are similarly more common in dogs after vagotomy. ${ }^{822}$ The vagus appears to act as a controlling influence on the normal gastric myoelectrical activity and removal of this influence creates an electrical environment where ectopic foci of activity can exist. These observations in humans support Daniel' $\mathrm{s}^{10}$ conclusions in dogs that the appearance of antral arrhythmias corresponds to the dominance of sympathetic over parasympathetic activity. It would appear that, as regular activity returned after the administration of atropine in those patients with both parasympathetically innervated and denervated antra who had long periods of irregular activity during the control recording period, it is unlikely that the parasympathetic innervation is the important factor in the generation and maintenance of the arrhythmias. If the irregular activity is due to sympathetic domination, then the effect of atropine could be explained by the cholinergic muscarinic blocking effect. Although low doses of intravenous atropine cause stimulation of the central vagal nucleus ${ }^{23}$ it is unlikely that the effect observed is vagally mediated, as it also occurred in one patient after total gastric vagotomy. Similar stabilisation of the arrhythmia in one patient by post-ganglionic sympathetic ß-receptor blockade with propranolol supports this concept.

The observation of arrhythmias after insulin may also be explained on the basis of sympathetic overactivity, hypoglycaemia per se being a potent stimulator of sympathetic neural discharge. Endogenous glucagon secretion also increases in hypoglycaemia, a significant increase being observed when the blood glucose falls below $3.9 \mathrm{mmol} / 1,{ }^{24}$ even when the pancreas has been vagally denervated after TV. ${ }^{24}$ Exogenous glucagon has been shown to inhibit gastric myoelectrical activity in the $\mathrm{dog},{ }^{26}$ this effect being mediated partly via an adrenergic pathway. It seems possible that the antral arrhythmias observed after exogenous glucagon may also be due to increased sympathetic activity.

Thus, in those subjects in this study in whom arrhythmias were observed, the effects could be explained by a relative increase of sympathetic over parasympathetic activity.

\section{References}

'Kwong NK, Brown BH, Whittaker GE, Duthie HL. Electrical activity of the gastric antrum in man. Br J Surg 1970; 57: 913-6.

${ }^{2}$ Couturier D, Roze C, Paolaggi J, Debray C. Electrical activity of the normal human stomach: a comparative study of the recordings obtained from the serosal and mucosal sides. Am J Dig Dis 1972; 17: 969-76.

${ }^{3}$ Carlson HC, Nelson RA, Code CF. Motor and electrical activity of the gastroduodenal junction. (Abstract) Fed Proc 1961; 20: 247.

${ }^{4}$ Daniel EE, Irwin J. Electrical activity of gastric musculature. In: Handbook of physiology. Washington DC: American Physiological Society, 1968: Section 6, Vol 4: 1969-86.

${ }^{5}$ Kelly KA, Code CF, Elveback LR. Patterns of canine gastric electrical activity. Am J Physiol 1969; 217: 461-70.

${ }^{6}$ Kelly KA and La Force RC. Pacing the canine stomach with electrical stimulation. Am J Physiol 1972; 222: 588-94.

${ }^{7}$ Nelsen TS, Eigenbrodt EH, Keoshian LA, Bunker C and Johnson L. Alterations in muscular and electrical activity of the stomach following vagotomy. Arch Surg 1967; 94: 821-35.

${ }^{8}$ Kelly KA, Code CF. Effect of transthoracic vagotomy on canine gastric electrical activity. Gastroenterology 1969; 57: 51-8.

${ }^{9}$ McCoy EJ, Bass P. Chronic electrical activity of the gastroduodenal area: effects of food and certain catecholamines. Am J Physiol 1963; 205: 439-45.

${ }^{10}$ Daniel EE. The electrical and contractile activity of the pyloric region in dogs and the effects of drugs. Gastroenterology 1965; 37: 268-81.

"Code CF, Marlett JA. Canine tachygastria. Mayo Clin Proc 1974; 49: 325-32.

${ }^{12}$ Morton HS. The potentialities of the electrogastrograph. Ann R Coll Surg Engl 1954; 15: 351-73.

${ }^{13}$ Goodman EN, Colcher H, Katz GM, Dangler CL. The clinical significance of the electrogastrogram. Gastroenterology 1955; 29: 598-608. 
${ }^{14}$ Nelsen TS and Kohatsu S. Clinical electrogastrography and its relationship to gastric surgery. Am J Surg 1968; 116: $215-22$

${ }^{15}$ Telander RL, Morgan KG, Kreulen DL, Schmalz PF, Kelly KA, Szurszewski JH. Human gastric atony with tachygastria and gastric retention. Gastroenterology 1978; 75: 497-501.

${ }^{16}$ You CH, Lee KY, Chey WY, Menguy R. Electrogastrographic study of patients with unexplained nausea, bloating and vomiting. Gastroenterology 1980; 79: 311-4.

${ }^{17}$ Stoddard $\mathrm{CJ}$. The effects of vagotomy on gastroduodenal myoelectrical activity. University of Sheffield: MD Thesis, 1977.

${ }^{18}$ Shiratori T. Sugawara K, Kuroda S. Surgical significance of pyloroplasty with special reference to electromyographic findings. Tohuku J Exp Med 1965; 85: 192-200.

${ }^{19}$ Hollander F. Laboratory procedures in the study of vagotomy (with particular reference to the insulin test). Gastroenterology 1948; 11: 419-25.

${ }^{20}$ Sarna SK, Daniel EE, Kingma YJ. Simulation of the electric control activity of the stomach by an array of relaxation oscillators. Am J Dig Dis 1972; 17: 299-310.

${ }^{21}$ Stoddard CJ, Smallwood R, Brown BH, Duthie HL. The immediate and delayed effects of different types of vagotomy on hyman gastric myoelectrical activity. Gut 1975; 16: $165-70$.

${ }^{22}$ Stoddard CJ, Brown BH and Duthie HL. The effects of varying the extent of vagotomy on the canine gastric and duodenal myoelectrical activity. (Abstract) $\mathrm{Br} J$ Surg 1973; 60: 913.

${ }^{23}$ Goodman LS, Gilman A. In: The pharmacological basis of therapeutics. New York: Macmillan, 1975: 515.

${ }^{24}$ Guyton HC. In: Textbook of medical physiology. Philadelphia: Saunders, 1966: 1084.

${ }^{25}$ Bloom SR. Glucagon. Br J Hosp Med 1975; 13: 150-8.

${ }^{26}$ Miolan JP, Roman C. Mechanisms of the inhibitory effects of glucagon on gastric motility. Proceedings of the 5th International Symposium on Gastroduodenal Motility, Leuven. Belgium. Typhof Press, 1975. 